\title{
Juventude em Foco: Representações Sociais da Juventude na Folha de S.Paulo
}

\author{
José Walter Rego Resende ${ }^{1}$ \\ Daniel Henrique Pereira Espíndula ${ }^{1}$

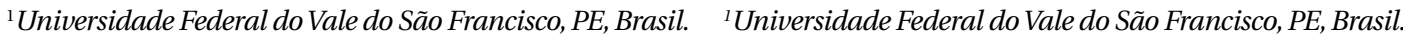

\begin{abstract}
Resumo: Este estudo é uma pesquisa documental que investigou as representações sociais da juventude em matérias do jornal Folha de S.Paulo. A busca pelas reportagens ocorreu no site do jornal, tendo como critério de inclusão os descritores "juventude" e "jovem", e terem sido publicadas no período de 1 de janeiro de 2014 a 31 de dezembro de 2014. Ao todo, foram registradas 165 reportagens sobre juventude e organizadas segundo as variáveis: a) ordem de entrada no banco; b) caderno; c) ano; e d) versão on-line ou impressa. Para análise dos dados, foram realizados três procedimentos: análise da classificação hierárquica descendente (CHD), análise de similitude do corpus textual das matérias por meio do software Iramuteq e, ainda, a análise de conteúdo de Bardin. Entre os resultados, destaca-se uma das representações sociais da mídia paulista sobre juventude evidenciada nas três análises, aquela relacionada a problemas envolvendo jovens. A representação social da juventude se ancora em um conhecimento socialmente partilhado sobre a figura negativa dos jovens sem formação ou qualificação profissional, de baixa renda e sem trabalho. Verificou-se também que a imprensa aponta aspectos que contemplem a ideia de juventudes: uma mais transitória, concebida pelos aspectos do desenvolvimento humano, como o desenvolvimento de habilidades, a entrada no mundo adulto e as perspectivas de futuro, e outra mais estanque, focada nos problemas e na falta de perspectivas juvenis.
\end{abstract}

Palavras-chave: Juventude, Representações Sociais, Jornal.

\section{Youth in Focus: Social Representations of Youth in Folha de S.Paulo}

\begin{abstract}
This documentary research investigated the social representations of the youth in matters of the newspaper Folha de S.Paulo. The search for the reports took place on the website of the newspaper, having as inclusion criteria the descriptors: "juventude”, "jovem" - published in the period between $01 / 01 / 2014$ and $12 / 31 / 2014$. A total of 165 youth reports were recorded and organized variables: a) number of entry into the bank, b) notebook, c) year and d) version online or printed. For data analysis, three procedures were performed: analysis of descending hierarchical classification, analysis of similarity of the textual corpus provided by the materials with use of the application software Iramuteq, as well as Bardin's content analysis. The results show one of the social representations of the São Paulo media about youth evidenced in the three analyses, related to problems involving young people. The social representation of youth is anchored in a socially shared knowledge of young people through negative information attributed to young people with no education or professional qualification, low income and no work. The press was also shown to point to aspects that contemplate the idea of youth: a more transient one, conceived by aspects of human development, such as development of skills, entry into the adult world and prospects for the future, and another, more conservative, focused on problems and lack of youth perspectives.
\end{abstract}

Keywords: Youth, Social Representations, Newspaper. 


\title{
Juventud en Foco: Representaciones Sociales de la Juventud en Folha de S.Paulo
}

\begin{abstract}
Resumen: El presente estudio es una investigación documental sobre las representaciones sociales de la juventud en materias del diario Folha de S.Paulo. La búsqueda de los reportajes ocurrió en el sitio web del periódico, teniendo como criterio de inclusión los descriptores: "juventud” y "joven”, publicados en el período del 01/01/2014 al 31/12/2014. En total se registraron 165 reportajes sobre juventud y organizados según las variables: a) orden de entrada en el banco, b) cuaderno, c) año y d) versión on line o impresa. Para el análisis de los datos, se realizaron tres procedimientos: análisis de la clasificación jerárquica descendente, análisis de similitud del corpus textual de las materias por medio del software Iramuteq y análisis de contenido de Bardin. En los resultados se destacan una de las representaciones sociales de los medios paulistas sobre juventud evidenciada en los tres análisis, la relacionada a problemas que involucra a jóvenes. La representación social de la juventud se ancla en un conocimiento socialmente compartido sobre la figura negativa de los jóvenes sin formación o cualificación profesional, de bajos ingresos y sin trabajo. Se verificó también que la prensa apunta a aspectos que contemplan la idea de juventudes: una más transitoria, concebida por los aspectos del desarrollo humano, como el desarrollo de habilidades, la entrada en el mundo adulto y las perspectivas para el futuro, y otra, más estanca, enfocada en problemas y falta de perspectivas juveniles.
\end{abstract}

Palabras clave: Juventud, Representaciones Sociales, Periódico.

\section{Introdução}

O tema juventude é bastante abordado pela imprensa, sendo constantemente noticiado e não raramente associado a assuntos relacionados com educação, violência, saúde, moda, religião, sexo, trabalho, estética, esporte e drogas (Lacerda \& Cruz, 2015; Rodrigues, Conceição, \& Iunes, 2015). Sobre os significados atribuídos à juventude, Doula (2013) destaca que, além de eles se relacionarem a aspectos como gênero, raça e classe social, vinculam-se a culturas e aspectos históricos e sociais, acarretando uma multiplicidade de significados atribuídos à juventude e, assim, trazendo a possibilidade de se pensar em juventudes.

Szapiro e Resende (2010) explicam que, até o final do século XX, o pensamento sobre a adultez era o modelo desejado socialmente. No entanto os autores salientam que essa ênfase vem sendo atribuída à juventude. Esta fase não representa mais um momento de transição da infância para a idade adulta. Existe uma busca, pelos sujeitos considerados adultos ou idosos, por um ideal de existência fomentado pelas características atribuídas ao conceito de juventude (Szapiro \& Resende, 2010).

Entender a juventude como parte integrante de uma sequência temporal com especificidades relacionadas a aspectos biológicos e sociais não implica em pensar, necessariamente, em uma sequência temporal de evolução linear. Leite e Ramalho (2015), por exemplo, compreendem que, mesmo considerando a juventude um tempo de especificidades, ela não deve ser entendida como a superação da infância e espera pela adultidade, ou que desconsidere as diferenças socioculturais de um país de dimensão continental como o Brasil, com toda sua diversidade e desigualdade econômica, cultural, social, racial etc.

Ao se considerar os vários sentidos e as críticas desenvolvidas ao termo e ao tema, Mortada (2009) destaca que juventude é um campo de estudo bastante atual e valorizado nas ciências humanas. $\mathrm{O}$ autor apresenta que, nos anos 1980, o tom das pesquisas realizadas sobre juventude era de caráter melancólico, especialmente ao analisar o engajamento político dos estudantes em comparação com os jovens das gerações anteriores. Ainda segundo o autor, foi a partir dos anos 1990 que a produção acadêmica sobre o tema muda de tom e foco. O movimento estudantil deixa de ser o principal referencial e são reconhecidas novas formas e espaços de engajamento crítico e político. O enfoque atual passa a ser marcado por um esforço de ruptura em relação a 1968, pelo combate a sua mitificação e ao peso que esta representa para as novas gerações. 
No que tange aos movimentos e estilos de juventude, Szapiro e Resende (2010) tecem uma crítica ao destacar que a juventude, considerada inicialmente como uma fase ou ciclo do desenvolvimento humano - portanto passageira e parte de um movimento contínuo e que daria lugar a outros momentos, como a velhice e a idade adulta - passou a ser concebida e buscada como um estado eterno. O imperativo social da juventude pode resultar em uma experiência acrítica dos valores, pois, para os autores, ser jovem é uma atividade permanente de se moldar como objeto de consumo, em uma lógica de mercado e consumo, ancorada na ideia da possibilidade de existência e felicidade associada à juventude. Desse modo, a juventude deixa de ser uma fase dentro do ciclo de desenvolvimento humano e passa a ser um modo de vida, um imperativo para conquistas e felicidade.

Alguns autores, a exemplo de Dayrell (2003), nomeiam esse movimento da constância e permanência da juventude como "a crise da juventude". Segundo Dayrell (2003), a vivência da crise seria, na verdade, mais da saída da juventude do que da entrada nessa fase. Destaca-se, aqui, a importância do construto juventude no campo das relações sociais e do desenvolvimento humano. A busca pela permanência na fase e o sofrimento por seu abandono forçam as ciências a repensarem as outras categorias do desenvolvimento, a saber, a infância e idade adulta.

A construção de um conceito, seja ele científico ou socialmente compartilhado, pode ser compreendida como uma arena de disputas simbólicas e políticas, o que é ratificado por Oliveira e Trancoso (2014). Os autores destacam que a formação dos conceitos sobre infância e juventude é, hoje, um processo capitaneado pelos adultos, os quais, por não estarem mais vivenciando tal fase, se mostram ao mesmo tempo familiares e estranhos a esse momento.

Com base nas perspectivas apresentadas sobre o tema juventude, verifica-se que o termo não se apresenta como uma maneira simples ou precisa de classificar um grupo - como o tempo -,tampouco como uma categoria de análise. $\mathrm{O}$ enfoque conferido está pautado em óticas distintas que se ancoram em aspectos sociais, biológicos, morais, políticos e culturais (Groppo, 2015; Mattos \& Castro, 2016; Szapiro \& Resende, 2010). Foi pensando na grande dimensão do tema juventude e na teoria das representações sociais (TRS) como de base psicossociológica, que se apresenta como ferramenta capaz de analisar o modo como os atores significam os fenômenos sociais em suas trocas cotidianas, que esta pesquisa se propôs a conhecer as representações sociais veiculadas e divulgadas pela mídia sobre juventude, tendo como base o jornal Folha de S.Paulo.

\section{A teoria das representações sociais e mídia}

De acordo com Vala (2004), o conceito de representação social diz respeito a uma produção de sentido comum a todas as sociedades, criada a partir da comunicação interindividual e alimentada tanto por teorias cientificas quanto por eixos culturais, ideologias, experiências e comunicações cotidianas. Moscovici (2012) salienta a necessidade de compreender as representações sociais pela via das interações entre os atores sociais. Para o autor, é a partir dessa possibilidade de conceber aspectos que os membros da sociedade percebem o mundo, suas ideias e relações, ou seja, por meio dos seus próprios comportamentos em sociedade.

Moscovici (2012) explica a representação social como um direcionamento para a ação, porque ela propicia a modificação e a reconstrução do ambiente, como também gera o comportamento. Para o autor, o humano é um ser capaz de se organizar e de elaborar questões, buscar respostas e compartilhar realidades por meio de elementos representativos.

Em seus estudos sobre o pensamento ambiente, Moscovici (2012) salienta duas funções das representações sociais: convencional e prescritiva. Na função convencional, observa-se que pessoas, objetos ou acontecimentos são colocados em um modelo, sendo, por meio dessas convenções, cada experiência somada à realidade na determinação prévia. Já em relação à segunda função prescritiva, verifica-se que as formas de pensar (repensar, recitar) dependem de conhecimentos anteriores. Com base nessas funções, inferir que os pensamentos são ideias configuradas em símbolos convencionais da realidade que estão expostos às influências da tradição, de memórias, costumes e conteúdos culturais. Assim, as representações sociais refletem na forma de pensar e em nosso próprio ambiente (social e cultural).

Em seu estudo sobre a representação social da psicanálise entre a sociedade francesa, Moscovici (2012) observou como as representações sociais produzem sistemas de comunicação profundamente diferentes no grupo. Este feito abriu a possibilidade 
de realizar pesquisas sobre comunicação em diversos contextos, a partir de modos e meios distintos.

Ao fazer alusão à mídia, Jodelet (2001) explica que a representação social desempenha um papel importante no processo de construção da realidade. Compreende-se que ela retrata, a seu modo, aspectos do cotidiano dos vários grupos sociais. Dentro dessa perspectiva, a imprensa tanto transmite e dissemina ideias, saberes e ideologias quanto produz, legitima e confere sentido às representações.

Jodelet (2001) destaca três pontos importantes examinados por Moscovici na importância da comunicação para a constituição de representações sociais: 1) é condição de possibilidade e determinação das representações sociais, sendo vetor de transmissão da linguagem, no qual veicula informações e interlocuções; 2) edifica condutas: opiniões, atitudes e estereótipos, sobre as quais repercutem os processos estruturais e formais do pensamento social; e 3) desempenha um papel fundamental nas trocas e interações que concorrem para a criação de um universo consensual, apoiadas na energética social e difundidas na vida dos grupos sociais.

Pesquisadores brasileiros desenvolveram investigações utilizando a TRS, enfocando a juventude e a mídia. Espíndula, Alves, Carvalho, Almeida e Cruz (2015) investigaram como a mídia representa e apresenta a relação entre o crack e adolescência/juventude. Cassab, Toledo, Ferreira e Rezende (2016) investigaram a forma como é construída a imagem dos jovens pobres e de seus bairros periféricos a partir da imprensa e como a mídia contribui para elaborar uma representação social dos jovens. Pimentel e Silva (2016) investigaram as situações de violência envolvendo jovens veiculadas na mídia impressa. Lacerda e Cruz (2015) buscaram compreender como se tem produzido visibilidade à política de abrigamento de jovens.

Este estudo analisou as representações sociais da juventude nas reportagens publicadas no jornal Folha de S.Paulo durante o ano de 2014. Considera-se que a análise das notícias veiculadas sobre juventude em um jornal de grande circulação nacional pode contribuir para a compreensão e o entendimento das representações sociais sobre esse objeto, permitindo interpretar e pensar como esse fenômeno é apresentado e representado pela mídia e por aqueles que a consomem.

O jornal analisado foi escolhido para este trabalho por assumir grande destaque na indústria das comunicações e ser, segundo a Associação Nacional de Jornais (2015), o jornal pago de maior circulação em formato digital do Brasil e considerado o terceiro maior em formato impresso. Já o ano de 2014 foi delimitado levando em consideração a data de 2 de fevereiro de 2014, em que entrou em vigor a Lei $\mathrm{n}^{\circ} 12.852 / 2013$, que instituiu o Estatuto da Juventude, inaugurando uma era de fortalecimento de políticas públicas que determinaram direitos aos jovens brasileiros garantidos pelo Estado.

\section{Método}

Trata-se de uma pesquisa descritiva com abordagem multimétodo, tendo como objeto de análise matérias publicadas no jornal Folha de S.Paulo durante o ano de 2014. A busca das reportagens ocorreu no site do jornal, considerando-se critério de inclusão os descritores "juventude" e "jovem". Como parâmetro de inclusão, consideraram-se as matérias publicadas na íntegra entre 1 de janeiro de 2014 a 31 de dezembro de 2014. Os critérios de exclusão foram: matérias incompletas e reportagens publicadas antes ou depois de 2014. Ao todo, foram identificadas 165 reportagens sobre juventude, organizadas segundo as seguintes variáveis: a) número de entrada no banco; b) caderno; c) ano; e d) versão on-line ou impressa. Cabe, aqui, considerar que, por se tratar de documentos públicos - reportagens publicadas em jornais sem a identificação de pessoas ou envolvimento de seres humanos - a realização do estudo não necessita de aprovação por parte de Comitê de Ética e Pesquisa, conforme as Resoluções no 466/2012 e no 510/2016.

Após a tabulação dos dados, o banco passou pelo processo de triangulação de análise de dados. Para Garnelo (2006), a triangulação de métodos se destaca como estratégia de diálogo entre áreas distintas de conhecimento, capaz de viabilizar o entrelaçamento entre teoria e prática e de agregar múltiplos pontos de vista. Segundo a autora, o emprego da técnica de triangulação exige a combinação de múltiplas estratégias de pesquisa capazes de apreender as dimensões qualitativas e quantitativas do objeto.

Denzin e Lincoln (2005) definem a triangulação a partir da combinação de diferentes metodologias na análise do mesmo fenômeno, de modo a consolidar a construção de teorias sociais, conferindo-se uma alternativa qualitativa, visando à validação de pesquisas que, ao utilizar múltiplos métodos, asseguram a compreensão mais profunda do fenômeno investigado (Zappellini \& Feuerschütte, 2015). Ainda, 
conforme Creswel (2007) e Günther (2006), o uso de mais de um procedimento de análise de dados, além de oferecer maior credibilidade à pesquisa, previne possíveis distorções e permite uma análise mais robusta aos resultados.

Nesse sentido, dentre os procedimentos de análise adotados está a análise de conteúdo de Bardin (2011), procedimento sistemático e objetivo composto por três fases: pré-análise, exploração do material e tratamento dos resultados (inferência e interpretação). Para Godoy (1995), a análise de conteúdo consiste em uma técnica metodológica em que o pesquisador busca compreender características, estruturas ou modelos subjacentes ao material analisado.

Ao apresentar as fases que compõem a análise de conteúdo, Câmara (2013) elenca três fases que compõem a análise de conteúdo. A primeira é a pré-análise, identificada como uma fase de organização em que são estabelecidos procedimentos bem definidos e flexíveis. É nesse momento que há um primeiro contato com os documentos que serão submetidos à análise - a leitura "flutuante", com a formulação das hipóteses e objetivos, e a elaboração dos indicadores que orientarão a interpretação e a preparação formal do material. Para tanto, segundo a autora, é preciso obedecer às regras de exaustividade (esgotar a totalidade da comunicação, não omitir nada); representatividade (a amostra deve representar o universo); homogeneidade (os dados devem se referir ao mesmo tema); pertinência (os documentos precisam se adaptar ao conteúdo e objetivo da pesquisa) e exclusividade (um elemento não deve ser classificado em mais de uma categoria).

Na segunda fase, exploração do material, são escolhidas as unidades de codificação e categorização (que permite reunir maior número de informações à custa de uma esquematização e, assim, correlacionar classes de acontecimentos para ordená-los). A partir da determinação das unidades de codificação, o passo seguinte é o tratamento dos resultados, com a classificação em blocos que expressem determinadas categorias.

A análise de corpus textual por meio da CHD, realizada pelo software Iramuteq, também compõe a análise de conteúdo. O Iramuteq agrega uma série de procedimentos estatísticos, os quais podem ser aplicados em bancos de dados textuais, como entrevistas, artigos de jornais, revistas diários de campo etc.

O método de análise do Iramuteq é composto por quatro etapas. A primeira diz respeito à análise do texto e ao cálculo dos dicionários. O programa classifica em ordem alfabética todo o vocabulário do banco de dados (corpus) e os agrupa segundo categorias de formas reduzidas (substantivo, verbo, adjetivo etc.). Na segunda etapa, são selecionados os termos com frequência $\geq 4$. É quando ocorre a CHD. Na terceira etapa, os valores obtidos na CHD são analisados e reanalisados para determinar os perfis das classes, definidas para partir do $\chi^{2}$ de associação das formas reduzidas às suas respectivas classes. Por último, na quarta etapa são construídas as listas das formas reduzidas associadas às classes e identificados os trechos das frases mais recorrentes em cada um dos contextos, nomeados pelo programa como "classes".

A análise de similitude de palavras presentes nas matérias é a terceira fase da análise de conteúdo e também é realizada por meio do software Iramuteq. Consiste na identificação de indicadores estatísticos que apresentam relações entre as palavras e as coocorrências entre os vocábulos, possibilitando identificar a estrutura da representação (Camargo \& Justo, 2013). A análise de similitude se constitui em outra modalidade de análise realizada pelo Iramuteq. Por meio de indicadores estatísticos são observadas as relações entre as palavras, em um gráfico chamado árvore máxima, como se dá a relação entre as palavras e se essas relações são fortes ou fracas. A força das relações é apresentada a partir do tipo de traço ou grafo: simples, duplo ou triplo. Quando mais largo o traço/grafo, maior a força de relação entre os termos.

Por fim Camargo e Justo (2013) destacam que o software Iramuteq é um programa de computador gratuito com fonte aberta, simples e compreensível que analisa textos, entrevistas, documentos etc. Permite ao pesquisador fazer análises estatísticas sobre corpus textuais, apresentando resultados de modos variados, como estatísticas textuais clássicas, pesquisas de especificidades, nuvem de palavras e, ainda, obtenção de classes de segmentos de texto que apresentam vocabulários semelhantes entre si.

\section{Resultados e discussão}

Inicialmente, serão apresentados os resultados relativos às análises realizadas pelo software Iramuteq. Em se tratando da análise da CHD, o corpus para análise foi constituído por 165 matérias, divididas em 781 unidades de conteúdo elementar (UCE), que correspondem ao número de palavras analisadas, das quais $76 \%$ foram consideradas para 
a análise de classificação hierárquica descendente, com 593 UCE analisadas.

Ao produzir o dendrograma, foi selecionado um valor de qui-quadrado quatro vezes maior do que o valor mínimo $\left(\chi^{2} \geq 11.50\right)$, a fim de trabalhar com uma margem de erro menor em cada associação da palavra com sua classe. É preciso lembrar que o $\chi^{2}$ é um teste de hipóteses que avalia a associação existente entre variáveis qualitativas. De modo geral, o teste é utilizado para verificar se a frequência de determinado evento observado em uma amostra se desvia significativamente ou não de sua frequência esperada. A frequência mínima considerada para produzir o dendrograma foi quarenta, de modo que apenas as palavras mais características de cada classe foram selecionadas para serem apresentadas graficamente. A frequência média de cada palavra e o valor $\chi^{2}$ podem ser visualizados na Figura 1.

\begin{tabular}{|c|c|c|c|c|c|c|c|c|}
\hline & \multicolumn{3}{|c|}{$\begin{array}{l}\text { Eixo 1: Visões antagônicas da } \\
\text { juventude }\end{array}$} & \multicolumn{3}{|c|}{$\begin{array}{r}\text { Eixo 2: Desenvolvimento } \\
\text { humano }\end{array}$} & & \\
\hline \multicolumn{3}{|c|}{$\begin{array}{l}\text { Classe 1: (+) Formação } \\
\text { profissional/Ensino 23,8\% }\end{array}$} & \multicolumn{3}{|c|}{$\begin{array}{l}\text { Classe 2: (-) } \\
\text { Violência/morte 29,7\% }\end{array}$} & \multicolumn{3}{|c|}{$\begin{array}{l}\text { Classe 3: Estilos de } \\
\text { juventude } 46,5 \%\end{array}$} \\
\hline Palavra & Freq. & $\mathrm{X}^{2}$ & Palavra & Freq. & $\mathrm{X}^{2}$ & Palavra & Freq. & $\mathrm{X}^{2}$ \\
\hline Ensino & 91,0 & 56,8 & Violência & 83,0 & 32,1 & Saber & 96,0 & 24,4 \\
\hline Programa & 82,0 & 33,1 & Problema & 100 & 31,4 & Vida & 83,0 & 23,4 \\
\hline Participar & 100 & 32,6 & Brasileiro & 78,0 & 31,3 & Falar & 90,0 & 22,7 \\
\hline Público & 59,0 & 24,4 & Populacão & 100 & 29,0 & Querer & 80,0 & 17,8 \\
\hline Escola & 72,0 & 24,0 & Sexual & 100 & 21,6 & Homem & 94,0 & 94,4 \\
\hline Movimento & 72,0 & 24,0 & Ano & 48,0 & 21,0 & Casa & 94,0 & 94,1 \\
\hline Desemprego & 100 & 22,7 & Pesquisa & 71,0 & 18,0 & Mulher & 86,0 & 13,4 \\
\hline Таха & 100 & 19,4 & Maior & 62,0 & 17,4 & Criança & 79,0 & 13,1 \\
\hline Qualidade & 100 & 19,4 & Manifestação & 83,0 & 16,8 & Adolescente & 93,0 & 12,3 \\
\hline Estratégia & 100 & 19,4 & Homicídio & 100 & 16,7 & História & 100 & 11,6 \\
\hline
\end{tabular}

Figura 1

Dendrograma da análise hierárquica descendente em relação às representações sociais das matérias sobre juventude.

A análise da CHD na Figura 1 originou dois eixos e três classes. O eixo 1 apresenta duas classes sobre as visões antagônicas da juventude. É possível notar que a classe 1 expõe aspectos positivos (o que corresponde a $23,8 \%$ do corpus inteiro), enquanto a classe 2 apresenta aspectos negativos ( $29,7 \%$ do corpus) da juventude.

O segundo eixo aborda a juventude por meio de uma concepção do desenvolvimento humano classe 3, aludindo aos estilos de juventude, representando 46,5\% do corpus analisado. A seguir, serão apresentadas as três classes com seus sentidos representacionais, UCEs, frequência média de cada palavra e o valor $\chi^{2}$.

\section{Classe 1: formação profissional/ensino}

Composta por 141 UCEs, correspondendo a $23,8 \%$ do corpus analisado. Apresenta atribuições positivas relacionadas à juventude. Seu conteúdo é agrupado em torno de palavras: ensino $\left(\chi^{2}=56,8\right)$, programa $\left(\chi^{2}=33,1\right)$, participar $\left(\chi^{2}=32,6\right)$, público $\left(\chi^{2}=24,4\right)$, escola $\left(\chi^{2}=24\right)$ e movimento $\left(\chi^{2}=24\right)$. Faz alusão à percepção da juventude no âmbito do ensino.

Esta classe apresenta a representação social da juventude para a formação profissional, que envolve os campos de trabalho, responsabilidade e seus desdobramentos, como independência e participação social.É uma classe informativa, na qual as ocorrências 
são respeitadas por meio de um olhar compreensivo para a juventude. Um exemplo de matéria publicada ilustra o discurso presente nesta classe:

Pobre da nação, contudo, que se contentar com universalizar um ensino de má qualidade e formar gerações de iletrados ou analfabetos funcionais o país todo tem de engajar-se na luta contra a condenação de sua juventude à pobreza intelectual (Folha de S.Paulo on line, 2014) ${ }^{1}$.

O enfoque conferido à juventude enfatiza sua importância e relação com a dinâmica coletiva do país. Essa lógica se ancora em ideias relacionadas à inserção dos jovens no contexto do trabalho e da educação. Mattos e Castro (2016) e Mayorga (2013) enfocam a dimensão de agente transformador da juventude capaz de introduzir mudanças reais na sociedade via educação e trabalho. Nesse sentido, os jovens são vistos como a possibilidade de renovação por meio do senso de responsabilidade pela mudança social.

\section{Classe 2: violência/morte}

Esta classe foi constituída por 176 UCEs, correspondendo a $29,7 \%$ do corpus analisado. Seu conteúdo é agrupado em torno das palavras: violência $\left(\chi^{2}=32,1\right)$ problema $\left(\chi^{2}=31,4\right)$, brasileiro $\left(\chi^{2}=31,3\right)$, população $\left(\chi^{2}=29\right)$, manifestação $\left(\chi^{2}=16,8\right)$ e homicídios $\left(\chi^{2}=16,7\right)$, tratando de assuntos relacionados à juventude ligados à violência e morte:

O Brasil produz o segundo maior número absoluto de homicídios de jovens (entre 0 a 19 anos) em todo o mundo. Perde apenas para a Nigéria. Em termos percentuais, ficamos atrás de El Salvador, Venezuela, e Guatemala (Vieira, 2014).

A relação entre juventude e violência resultando em mortes mais uma vez se faz presente nos resultados de pesquisas. No que tange a essa problemática, salienta-se que tal fenômeno não é exclusividade do Brasil. Embora outros países apresentem problemas relacionados à criminalização de jovens, o Brasil surge como um dos países com maior registro de casos.

O Atlas da violência de 2018 (Cerqueira et al., 2018) denuncia que a morte de jovens no país é um fenômeno que vem sendo denunciado nas últimas décadas e permanece sem a devida resposta no que tange às políticas públicas setoriais. Ainda segundo o relatório, no decênio 2006-2016, houve aumento de $23,3 \%$ do número de mortes de jovens, sobretudo de homens e negros, e que, em 2016, vinte estados apresentaram aumento do número de mortes. Em consonância com relatórios públicos, esses achados escancaram a vulnerabilidade à qual esse público está exposto, justamente por ser reconhecido pelo marcador social de jovem.

Corrêa e Souza (2011) salientam que o grupamento da juventude é um dos expostos a violências externas, fruto da desigualdade socioeconômica. Ainda segundo os autores, se a população fosse dividida em dois grupos - os jovens de 15 a 24 anos e os "não-jovens", demarcados pelas crianças e parte da adolescência $(0 \mathrm{a}$ 15 anos) juntamente com os adultos e idosos - haveria na população "não-jovem" 9,8\% de mortes por causas externas, enquanto entre os jovens, menor segmento populacional, $72 \%$ de mortes por causas externas.

Waiselfisz (2016) destaca o progressivo e ininterrupto incremento das taxas de homicídio por arma de fogo envolvendo jovens: $592,8 \%$ se comparado aos dados colhidos em 1980. Já os suicídios com armas de fogo envolvendo jovens aumentaram $44,8 \%$, e as mortes acidentais caíram $3,6 \%$. Ainda segundo o autor, as mortes por armas de fogo de causalidade indeterminada entre jovens, isto é, sem especificação (suicídio, homicídio ou acidente), tiveram queda moderada de $20,4 \%$.

\section{Classe 3: estilos de juventude}

É composta por 276 UCEs, correspondendo a 46,5\% do total do corpus. O conteúdo foi agrupado em torno de: saber $\left(\chi^{2}=24,4\right)$, vida $\left(\chi^{2}=23,4\right)$, falar $\left(\chi^{2}=22,7\right)$, querer $\left(\chi^{2}=17,8\right)$, homem $\left(\chi^{2}=94,4\right)$, casa $\left(\chi^{2}=94,1\right)$, mulher $\left(\chi^{2}=13,4\right)$, criança $\left(\chi^{2}=13,1\right)$, adolescente $\left(\chi^{2}=12,3\right)$ e história $\left(\chi^{2}=11,6\right)$. Versa sobre juventude a partir da socialização e desenvolvimento humano.

Adolescentes gostam de andar em bando e, nos condomínios, dá gosto de ver as turmas que se formam. Amizades são construídas, muitas vezes, para a vida toda. É o que chamo de "geração condomínio", de jovens que já nascem preparados para viver em coletividade. Entre amigos, eles curtem as áreas comuns e passam horas conversando, brin-

${ }^{1}$ Editorial, 12 de dezembro de 2014. https://wwwl.folha.uol.com.br/opiniao/2014/12/1561250-editorial-a-lingua-condenada.shtml 
cando e, às vezes, aprontando. A frase "vou descer e já volto", por exemplo, é uma velha conhecida das famílias. Cultivar amizade com os vizinhos faz bem aos jovens e traz sossego aos pais. Nos empreendimentos do tipo "clube", com equipadas áreas de lazer, tudo fica mais fácil. Já nos condomínios que não têm áreas comuns específicas para a molecada, os adultos precisam ter consciência de que os jovens gostam e precisam conviver em grupo. Nesse caso, moradores e gestores devem ter iniciativa e criatividade para transformar qualquer espaço comum em áreas minimamente equipadas para os adolescentes (Rachkorsky, 2014).

Tais achados denotam o modo como o jornal pesquisado significa a ideia de juventude pela idade cronológica (aspectos biológicos) e redes de amizades e interação (aspectos sociais). Essas ideias estão ancoradas em discursos a respeito da importância do desenvolvimento físico e social dos jovens. A imprensa alude para o fato de que a juventude se expressa mediante a construção de estilos e modos de vida em que são realizadas ações individuais ou coletivas pelos jovens.

Alguns estudos destacam a busca dos jovens por algo que lhes garanta sentido prático à vida (Mattos \& Castro, 2016; Taquetti, 2010). Segundo os autores, durante a juventude existe a influência de aspectos psicossociais, como a busca identitária, tendência de estar em grupo, "intelectualização" dos fatos e o questionamento dos valores sociais.

A análise de similitude também agrupou o material selecionado em torno de três classes: 1) Direitos sociais e liberdade; 2) Problemas; e 3) Desenvolvimento humano, conforme ilustrado na Figura 2.

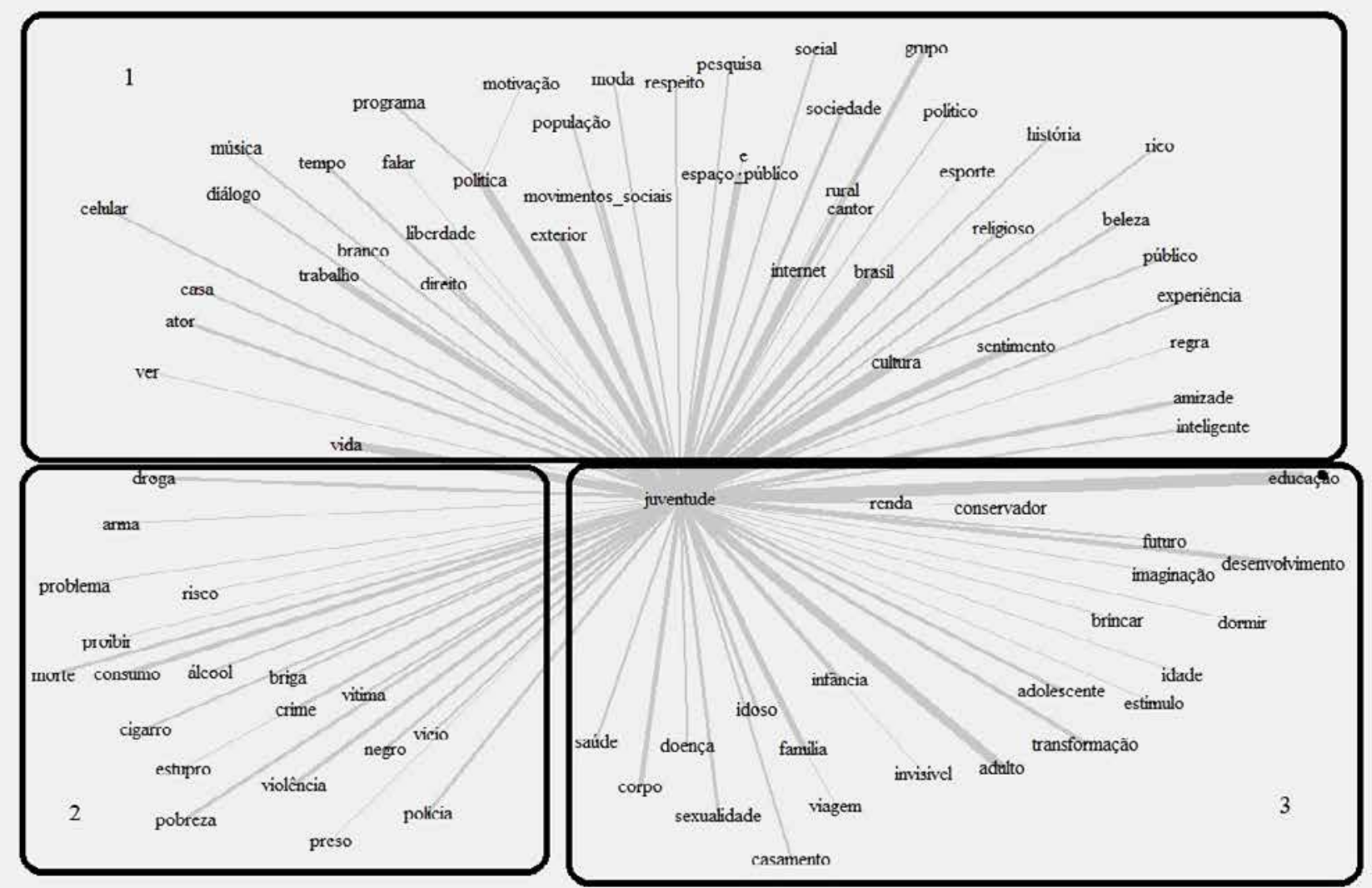

Figura 2

Análise de similitude de palavras relacionadas às matérias sobre juventude.

A primeira classe, nomeado aqui de Direitos sociais e liberdade, foi responsável por concentrar o maior número de elementos textuais. Diz respeito às características relacionadas à garantia de direitos, os quais são assegurados aos jovens e estão presentes no Estatuto da Juventude (Brasil, 2013). 
A mídia ancora ideias sobre juventude relacionadas à liberdade, ao trabalho, à cultura, a espaços públicos e ao processo de inserção em esferas e segmentos sociais dos jovens por meio da conquista de direitos, objetivados em investimentos que fazem os jovens ser vistos como membros economicamente ativos, capazes de introduzir mudanças reais na sociedade. Diante isso, Mayorga, (2013) enfatiza que a participação pública e coletiva dos jovens em projetos que atravessam questões como desemprego, segurança e formação profissional favorece a sociabilidade e produção de saberes que dão voz a ações e experiências juvenis.

A segunda classe - Problemas - apresentou menor concentração quanto ao número de palavras e coocorrências. Aqui a referência está ligada aos problemas vivenciados pela juventude: morte, drogas, armas, álcool, violência, crime etc. Essa classe é representada e objetivada na imagem de jovens negros, sem formação/estudo, que manejam armas de fogo e são usuários de drogas.

Alberto (2012) destaca que, no âmbito da Psicologia do Desenvolvimento, as práticas direcionadas à infância e juventude eram voltadas, inicialmente, para dois modelos: clínico diferencial focado em diagnostico, cura e tratamento - e escolar - que separa os "aptos" dos "não aptos" para a aprendizagem. Tais práticas psicológicas se destinavam ao controle dos sujeitos por meio do emprego da disciplina ou da valorização de um suposto indivíduo autônomo. Em contraponto, outro campo de saberes e técnicas se desenvolveu: o da patologização da infância e da juventude.

Ao considerar as duas classes a partir da concepção teórica da existência de juventudes na sua expressão grupal, o jornal em questão segue por essa vertente ao apresentar duas possibilidades distintas da vivência da juventude. O primeiro, positivado, alusivo à classe média e às mais abastadas, representadas pela ideia de futuro e educação, e o segundo, negativado, alusivo às camadas mais populares e excluídas. Tais achados convergem com os resultados de Santos, Aléssio e Silva (2009), em que jovens pertencentes à classe baixa são destacados pela imprensa como os principais autores da violência, sem se debruçar sobre a história dos personagens, legitimando a associação pobreza-violência.

A terceira classe expõe aspectos do Desenvolvimento humano, entre eles aspectos físicos (o corpo), intelectuais (imaginação), afetivo-emocionais (sexualidade), sociais (estímulos), incluindo habilidades motoras (brincar). Alude a uma representação ancorada no desenvolvimento e bem-estar humano: saúde, educação, família, renda, casamento, futuro etc., a partir do ciclo de desenvolvimento humano infância, adolescência, adultez e velhice.

Os resultados encontrados a partir da análise de similitude apresentam um conjunto de informações veiculadas sobre juventude que completam as informações obtidas por meio da análise de CHD. De modo semelhante à análise apresentada pela CHD, organizando as ideias de juventude em torno de elementos negativos, positivos e estilos de vida, a análise de similitude foi capaz de ratificar a demarcação do arranjo simbólico na condição socioeconômica - os mais favorecidos e os desfavorecidos -, apontando que os estilos juvenis estão mais associados às parcelas mais favorecidas, aludindo a uma lógica desenvolvimentista. Ao que parece, a concepção empregada e difundida pelo campo da psicologia do desenvolvimento se aplica a uma parte da juventude, com garantia de acesso à educação e crença de futuro, aos demais, não.

A terceira modalidade de tratamento adotada no banco de dados visando à triangulação foi a análise de conteúdo. Os resultados apontaram para um agrupamento em torno de três categorias: a) educação; b) problemas; e c) juventudes. A Tabela 1 apresenta as categorias formadas e suas subcategorias.

\section{Tabela 1}

Análise de conteúdo: matérias sobre juventude no jornal Folha de S.Paulo, 2014

\begin{tabular}{lcc}
\hline Categorias & Frequência & $\%$ \\
\hline I. Educação/ensino & & \\
I.1. Formação profissional & 128 & $13,63 \%$ \\
I.2. Compromisso & 78 & $8,31 \%$ \\
I.3. Espaços de ensino & 57 & $6,07 \%$ \\
I.4. Renda & 39 & $4,15 \%$ \\
I.5. Tempo/dedicação & 21 & $2,24 \%$ \\
I.6. Transformação social & 11 & $1,17 \%$ \\
Subtotal & 334 & $35,57 \%$ \\
\hline & & \\
\hline II. Problemas & & \\
II.1.Violência & 82 & $8,73 \%$ \\
II.2. Desemprego & 46 & $4,90 \%$ \\
\hline & & continua...
\end{tabular}




\begin{tabular}{|c|c|c|}
\hline Categorias & Frequência & $\%$ \\
\hline II.3. Família como base & 45 & $4,79 \%$ \\
\hline II.4. Drogas & 38 & $4,05 \%$ \\
\hline II.5. Suicídio & 25 & $2,67 \%$ \\
\hline II.6. Baixa renda/pobreza & 18 & $1,92 \%$ \\
\hline II.7. ISTs & 13 & $1,38 \%$ \\
\hline II.8. Prostituição & 11 & $1,17 \%$ \\
\hline II.9. Preconceito & 7 & $0,74 \%$ \\
\hline Subtotal & 285 & $30,35 \%$ \\
\hline \multicolumn{3}{|l|}{ III. Juventudes } \\
\hline III.1. Diversidade & 58 & $6,18 \%$ \\
\hline III.2. Internet/mídia & 54 & $5,75 \%$ \\
\hline III.3. Corpo/beleza & 36 & $3,83 \%$ \\
\hline $\begin{array}{l}\text { III.4. Estabilidade afetiva/ } \\
\text { financeira }\end{array}$ & 29 & $3,09 \%$ \\
\hline III.5. Efêmero/passageiro & 28 & $2,97 \%$ \\
\hline III.6. Identidade & 27 & $2,88 \%$ \\
\hline $\begin{array}{l}\text { III.7. Relações amorosas/ } \\
\text { sexuais }\end{array}$ & 27 & $2,88 \%$ \\
\hline III.8. Morte & 26 & $2,77 \%$ \\
\hline $\begin{array}{l}\text { III.9. Maternidade/ } \\
\text { paternidade }\end{array}$ & 23 & $2,45 \%$ \\
\hline IV.10. Ingresso na vida social & 8 & $0,85 \%$ \\
\hline IV.11. Religião & 4 & $0,43 \%$ \\
\hline Subtotal & 320 & $34,08 \%$ \\
\hline Total & 939 & $100 \%$ \\
\hline
\end{tabular}

A primeira categoria, Educação, foi composta por $35,57 \%$ de elementos textuais e de seis subcategorias: formação profissional $(n=128)$, compromisso $(n=78)$, espaços de ensino $(n=57)$, renda $(n=39)$, tempo/dedicação $(n=21)$ e transformação social $(n=11)$. Essa categoria alude ao tema da formação profissional e qualificação do jovem no que tange à busca por qualificação profissional e ingresso no mercado de trabalho. Durante essa análise, serão apresentados trechos selecionados capazes de exemplificar a ideia contida em cada classe.

No nível educacional é necessário destacar que somente $13 \%$ dos jovens seguiram ir até o ensino superior, sendo que $16 \%$ atingiram o ensino fundamental completo, $11 \%$ concluíram o fundamental, $21 \%$ o ensino médio incompleto e $38 \%$ conseguiram concluir o ensino médio (Moussallem, 2014).

Essa representação se ancora na ideia de ensino e nos locais onde ocorre a dispersão do conhecimento entre os jovens, como escolas e universidades. Contudo, mesmo existindo espaços para o ensino, a categoria sinaliza motivos nos quais se pode pensar o que dificulta a investidura de alguns jovens em um curso superior: tempo/dedicação e renda. Em relação a isso, Menandro, Trindade e Almeida (2010) salientam que alguns jovens não se dispõem a ingressar em estágios preparatórios para um futuro profissional, mostrando assim que nem todos eles encaram a juventude como um momento de preparação de formação profissional para as etapas futuras da vida.

A categoria apresentada completa as ideias expostas tanto pela análise da CHD quanto pela análise de similitude. Ambas enfatizam o ensino/formação na vida dos jovens como possibilidade de crescimento, ascensão, valorização e transformação social. No entanto foi por meio da análise de conteúdo que se verificou mais vez o condicionante socioeconômico demarcando as existências juvenis. Para o jornal analisado, o fator financeiro é o elemento determinante no interesse em dar continuidade à trajetória estudantil e na busca por formação profissional.

A segunda categoria, Problemas, congregou $30,35 \%$ dos conteúdos textuais presentes nas matérias sobre juventude e foi composta por nove subcategorias: violência $(n=82)$, desemprego $(n=46)$, família $(\mathrm{n}=45)$, drogas $(\mathrm{n}=38)$, suicídio $(\mathrm{n}=25)$, baixa renda/ pobreza $(n=18)$, ISTs $(n=13)$, prostituição $(n=11)$ e preconceito $(n=7)$. Essa categoria aponta para a juventude tanto vítima quanto coautora de problemas. O trecho a seguir, de uma matéria publicada, exemplificam a formação dessa categoria.

Estamos perdendo a guerra contra as drogas porque o consumo está aumentando e porque há dois novos problemas: a violência do tráfico e a repressão a jovens usuários, presos como traficantes, que ficam com as vidas marcadas para sempre. Nesse entendimento, estamos parecidos com os EUA. Mas estamos longe da clareza deles sobre como regulamentar o uso da cannabis (Mena, 2014).

A Folha de S.Paulo expõe a imagem de uma juventude que se reflete na tensão entre protagonismo e vitimização. Verifica-se que os problemas (violência, uso e abuso de drogas) apresentados nessa categoria partem da análise dos contextos nos quais estão inseridos alguns jovens. Observa-se que os problemas que 
envolvem a juventude parecem se referir ao perfil de jovens de baixa renda. Essa ideia dialoga com os resultados das classes 1 (Formação profissional/ensino) e 2 (Morte por causa externa/violência) da CHD, que apresentaram visões positiva e negativa da mídia no que diz respeito à juventude pobre e vitimada.

Embora o Estado possa ser responsabilizado pela ausência ou baixa efetividade de políticas públicas que diminuam os problemas vivenciados pela juventude, a mídia utiliza uma representação associada ao perfil de jovem pobre e sem formação como o responsável por desencadear, cometer ou se envolver em problemas. A esse respeito, Valesan (2015) destaca que, quando não há a adoção de normas e políticas notadamente capazes de oferecer alternativas de mediação para os conflitos que tencionam a juventude, as desigualdades promovem injustiças visíveis.

Já a terceira categoria, Juventudes, agrupou $34,08 \%$ de todo o conteúdo textual das matérias, sendo composta por onze subcategorias: diversidade ( $n=58)$, internet $/$ mídia $(n=54)$, corpo/beleza $(n=36)$, estabilidade afetiva/financeira $(n=29)$, efêmero/passageiro $(n=28)$, identidade $(n=27)$, relações amorosas/sexuais $(\mathrm{n}=27)$, morte $(\mathrm{n}=26)$, maternidade/ paternidade $(n=23)$, ingresso na vida social $(n=8)$ e religião $(n=4)$. Apresenta ideias relacionadas à diversidade de significados sobre juventude, ao pluralismo de conceitos e de características a respeito desse fenômeno. Seguem dois exemplos de trechos de reportagens que fazem alusão à categoria apresentada:

Mas o fato principal foram as dramáticas mudanças vivenciadas nos últimos 20 anos, onde é absolutamente normal e, talvez até esperado, que uma jovem dedique seus anos dourados reprodutivos, privilegiando não só sua carreira, mas sua ascensão pessoal, cultural e emocional, de modo que as relações conjugais, se iniciam mais tarde (Collucci, 2014).

O que se verifica é uma representação social baseada em uma concepção de juventude como o tempo de transição em que o ser humano vive um momento autônomo, com sentidos próprios, e não somente como uma fase de preparação para a fase seguinte da vida. Nesse sentido, a mídia desempenha papel fundamental na ancoragem das representações sociais sobre juventude e na definição dos modos de vivência desse fenômeno, retratando o jovem como alguém em desenvolvimento e vivenciando situações e sentimentos diferentes.

Nos estudos sobre mídia e juventude (Espíndula et al., 2015, Menandro et al., 2010), a imprensa retrata a realidade dos jovens para a população de forma geral e as representações perpassadas giram em torno de uma lógica que presume que a juventude esteja para além de uma fase específica da vida. Tais concepções reforçam os achados da classe 3 da análise de similitude, Juventudes, que apresenta a ideia da existência de uma pluralidade de juventudes ao atentar para o fato de que a mídia se refere a esse período por meio de um conjunto de aspectos não somente biológicos, mas também culturais e sociais, experiências de vida e a momentos compartilhados.

Os métodos de análise empregados nessa investigação forneceram subsídios para uma compreensão mais profunda das representações sociais da mídia sobre juventude. A CHD proporcionou a avaliação da inter-relação entre as classes de palavras presentes no discurso da mídia sobre juventude a partir do cruzamento entre as UCEs das classes e as formas reduzidas características da mesma classe. Com o auxílio da análise de similitude, foi possível identificar as coocorrências de palavras por meio dos elementos de significados mais próximos, viabilizando a identificação da estrutura das representações sociais. Já a análise de conteúdo possibilitou a formação de categorias mais gerais de conteúdo, trabalhando os sinônimos menos utilizados, o que supriu uma lacuna do programa Iramuteq, uma vez que este considera (no corte inicial) apenas as palavras do corpus textual com frequência mínima previamente estabelecida. Diante disso, compartilhamos o pensamento dos autores Almeida (2005) e Farr (2002), que atentam para o fato de que o caráter plurimetodológico da pesquisa no campo das representações sociais torna possível o emprego de uma ampla variedade de métodos e técnicas de análise.

As análises aqui empregadas se complementaram para explorar ao máximo o fenômeno estudado, resultando em uma representação social da juventude voltada para a existência de pelo menos duas concepções diferenciadas de juventude. A demarcação entre essas possibilidades não é realizada pelo delineamento identitário estabelecido entre os jovens em suas relações e trocas sociais, mas por condicionantes sociais, sendo, portanto, delimitada pela renda. Isso implica dizer que o modo de experienciar a juventude e seus estilos é determinado não pelas escolhas 
iniciais do ator que vivencia a fase - o jovem -, mas por sua condição financeira. Todos os outros elementos associados ao jovem e à juventude - perspectivas de futuro, formação/qualificação profissional, redes de socialização, saúde, qualidade de vida, lazer e riscos são opostos e diferentes entre os das classes menos favorecidas e dos de classe média e mais abastadas.

\section{Considerações finais}

Para o propósito desta pesquisa, o conteúdo do texto das matérias analisadas foi considerado como expressão da representação social do jornal Folha de S.Paulo sobre juventude. O estudo documental foi o meio encontrado para compreender as representações sociais da juventude apresentadas pela impressa. De maneira geral, não se considerou a mídia apenas como veículo condutor das ideias e pensamentos do emissor para o receptor, mas como instrumento (re) produtor de saberes capaz de orientar condutas e construir significados partilhados socialmente.

Os resultados encontrados nessa pesquisa convergem com os encontrados por Menandro et al. (2010), que destacam que juventude é um tema de reflexão e intervenção, uma vez que as informações sobre juventude veiculadas pela mídia estão em estreita ligação com a contextura social na qual acontece. Essas observações, como ressaltam Mattos e Castro (2016), devem-se ao fato de haver incidência de informações positivas ou negativas relacionadas à juventude. É pensando nisso que Moscovici (2012) considera a mídia como detentora de papel ativo na difusão do saber, uma vez que ela mesma estabelece uma ordem para capacitar os indivíduos a se orientar em seu mundo material e social e controlá-lo.

A ênfase conferida aos meios de comunicação na produção da realidade nos faz entender o pensamento de Rodrigues et al. (2015), ao considerarem que os conteúdos informativos divulgados pela mídia seriam os pilares da construção da realidade e que os meios de comunicação seriam produto e parte integrante do conhecimento social. Estas relações se fazem presentes quando observamos os elementos de objetivação sobre as representações da juventude identificados neste estudo pela imprensa: a) formação profissional; b) problemas; e c) estilos de juventude.

Entre os elementos apresentados pela mídia envolvendo juventude, destaca-se aquele que merece maior atenção - problemas. Este elemento representacional da juventude está ancorado na crença do jovem despreocupado com o futuro e não interessado com a busca pela entrada no mercado de trabalho e por formação profissional, que marcam o ser adulto. Nessa concepção, o jovem de baixa renda, sem trabalho e instrução profissional, constitui a imagem/objetivação do jovem-problema.

Percebe-se que tal representação social está engendrada na complexidade das determinações econômicas, sociais e educacionais que existem no país. Essa visão só agrava o hiato e a segregação social entre os jovens e as perspectivas de futuro, porque, segundo pesquisa publicada pela Unicef (Fundo das Nações Unidas para a Infância, 2018), seis em cada dez crianças e adolescentes brasileiros vivem em situação de pobreza. Segundo o levantamento, a pobreza que acomete a maioria dos adolescentes brasileiros não é apenas monetária, mas são múltiplas as facetas de privações: saúde, educação, informação, moradia etc. Em razão disso, é importante repensar os papéis sociais estabelecidos à juventude atualmente, visto que o Brasil é um país demograficamente jovem, mas que compromete sua população com uma perspectiva negativista e oferecendo pouca perspectiva de futuro.

Por fim, esta pesquisa não teve como objetivo analisar a representação da juventude em diferentes veículos de comunicação, sendo restrita a um canal de comunicação, o que indica a necessidade de distintas investigações futuras - seria interessante verificar o tipo de conteúdo veiculado por outros tipos de mídia. Pontua-se ainda que o uso da técnica de triangulação metodológica empregada neste estudo proporcionou uma visão mais ampla para a compreensão do objeto analisado, uma vez que conferiu mais robustez, coerência e coesão para a discussão dos resultados. Todavia atentamos para o fato de que o uso da triangulação reduz as chances de erro de uma pesquisa, mas não o elimina, cabendo ao pesquisador atenção em todos os procedimentos empregados. 


\section{Referências}

Alberto, M. F. P. (2012). Pensamento crítico, formação de psicólogo e atuação junto à infância e juventude. Estudos de Psicologia (Natal), 17(3), 421-426.

Almeida, A. M. O. (2005). A pesquisa em representações sociais: proposições teórico-metodológicas. In M. F. S. Santos \& L. M. Almeida (Orgs.), Diálogos com a teoria da representação social (pp. 117-160). Recife, PE: EDUFPE/EDUFAL.

Associação Nacional de Jornais. (2015). Maiores jornais do Brasil. http:/ /www.anj.org.br

Bardin, L. (2011). Análise de conteúdo (6a ed.). Lisboa: Edições 70.

Brasil. (2013). Lei no 12.852, de 5 de agosto de 2013. Institui o Estatuto da Juventude e dispõe sobre os direitos dos jovens, os princípios e diretrizes das políticas públicas de juventude e o sistema nacional de juventude. Brasília, DF: Casa Civil. https://www.planalto.gov.br/ccivil_03/_ato2011-2014/2013/lei/112852.htm

Collucci, C. (2014, 23 de outubro). Cabe a cada mulher decidir pelo congelamento de óvulos. Folha de S.Paulo. https://wwwl.folha.uol.com.br/colunas/claudiacollucci/2014/10/1536960-cabe-a-cada-mulher-decidir-pelocongelamento-de-ovulos.shtml

Câmara, R. H. (2013). Análise de conteúdo: da teoria à prática em pesquisas sociais aplicadas às organizações. Gerais: Revista Interinstitucional de Psicologia, 6(2), 179-191.

Camargo, B. V., \& Justo, A. M. (2013). IRAMUTEQ: um software gratuito para análise de dados textuais. Temas em Psicologia, 21(2), 513-518.

Cassab, C., Toledo, J. A. C., Ferreira, K. O., \& Rezende, R. P. (2016). Representações na mídia da juventude e a produção do medo: experiência em uma cidade média brasileira. Finisterra: Revista Portuguesa de Geografia, 102(1), 103-120.

Cerqueira, D., Lima, R. S., Bueno, S., Neme, C., Ferreira, H., Coelho, D., Alves, P. P., Pinheiro, M., Astolfi, R., Marques, D., Reis, M., \& Merian, F. (2018). Atlas da violência 2018. Rio de Janeiro, RJ: Ipea. https://www.ipea.gov.br/portal/ images/stories/PDFs/relatorio_institucional/180604_atlas_da_violencia_2018.pdf

Corrêa, C. S., \& Souza, S. J. (2011). Violência e vulnerabilidades: os jovens e as notícias de jornal. Fractal: Revista de Psicologia, 23(3), 461-486.

Creswel, J.W. (2007). Projeto de pesquisa: método qualitativo, quantitativo e misto (2a ed.). Porto Alegre, RS: Artmed.

Dayrell, J. (2003). O jovem como sujeito social. Revista Brasileira de Educação, 24, 40-52.

Denzin, N. K., \& Linconl, Y. S. (2005). Introduction: the discipline and practice of qualitative research. In N. K. Denzin \&Y. S. Linconl (Orgs.), The Sage handbook of qualitative research (pp. 1-32). Thousand Oaks: Sage.

Doula, S. M. (2013). Família, escola e juventude nos debates sobre a cultura contemporânea. Educação em Revista, 29(1), 305-310.

Espíndula, D. H. P., Alves, L.S., Carvalho, L. A., Almeida, M. B., \& Cruz, S. T. M. (2015). Representações sociais de crack e adolescência na imprensa pernambucana. Temas em Psicologia, 23(2), 281-292.

Farr, R. M. (2002). Representações sociais: a teoria e sua história. In P. Guareschi \& S. Jovchelovitch (Orgs.), Textos em representações sociais (7a ed., pp. 31-59). Petrópolis, RJ: Vozes.

Fundo das Nações Unidas para a Infância. (2018). Pobreza na infância e na adolescência. https://www.unicef.org/ brazil/relatorios/pobreza-na-infancia-e-na-adolescencia

Garnelo, L. (2006). Avaliação por triangulação de métodos: abordagem de programas sociais. Cadernos de Saúde Pública, 22(5), 1115-1117.

Godoy, A. S. (1995). Pesquisa qualitativa: tipos fundamentais. Revista de Administração de Empresas, 35(4), 65-71.

Groppo, L. A. (2015). Teorias pós-críticas da juventude: juvenilização, tribalismo e socialização ativa. Revista Latinoamericana de Ciencias Sociales, Niñez y Juventud, 13 (2), 567-579.

Günther, H. (2006). Pesquisa qualitativa versus pesquisa quantitativa: esta é a questão? Psicologia: Teoria e Pesquisa, 22(2), 201-210.

Jodelet, D. (2001). Representações sociais: um domínio em expansão. In D. Jodelet (Ed.), As representações sociais (L. Ulup, Trad., pp. 187-203). Rio de Janeiro, RJ: EdUERJ.

Lacerda, S. T., \& Cruz, L. M. F. (2015). Juventude pobre e o acolhimento institucional: os sentidos compartilhados na mídia impressa em Pernambuco. Tópicos Educacionais, 21(1), 250-282. 
Leite, L. H. A., \& Ramalho, B. (2015). Jovens-adolescentes egressos de uma educação integral: a construção de atitudes e valores. Educação em Revista, 31(4), 63-80.

Mattos, A. R., \& Castro, L. R. (2016). Jovens e a liberdade: reflexões sobre autonomia, responsabilidade e independência. Psicologia \& Sociedade, 28(1), 65-73.

Mayorga, C. (2013). Pesquisar a juventude e sua relação com a política: notas metodológicas. Estudos de Psicologia (Natal), 18(2), 343-350.

Mena, Fernanda. (2014, 15 de novembro). Maconha para fins médicos deve ser facilitada, diz Cristovam Buarque. Folha de S.Paulo. http://www1.folha.uol.com.br/cotidiano/2014/11/1548629-maconha-para-fins-medicos-deve-ser-facilitada-diz-cristovam-buarque.shtml

Menandro, M. C. S., Trindade, Z. A., \& Almeida, A. M. O. (2010). Gente jovem reunida: representações sociais da adolescência/juventude em textos jornalísticos. Vitória, ES: GM Editora.

Mortada, S. P. (2009). De jovem a estudante: apontamentos críticos. Psicologia \& Sociedade, 21(3), 373-382.

Moscovici, S. (2012). A psicanálise, sua imagem e seu público. Petrópolis, RJ: Vozes.

Moussallem, M. (2014, 23 de abril). Juventude brasileira: urgência no debate público. Folha de S.Paulo. http:// wwwl.folha.uol.com.br/empreendedorsocial/colunas/2014/04/1444377-juventude-brasileira-urgencia-no-debate-publico.shtml

Oliveira, A. A. S., \& Trancoso, A. E. R. (2014). Processo de produção psicossocial de conceitos: infância, juventude e cultura. Psicologia \& Sociedade, 26(spe2), 18-27

Pimentel, T. P., \& Silva, L. I. C. (2016). Situações e representações sobre adolescência, juventude e violência: um estudo qualitativo a partir da mídia impressa paraense. Revista Conexão de Saberes, 1(1), 31-36.

Rachkorsky, M. (2014, 25 de maio). Turma da pesada no condomínio. Folha de S.Paulo. http://m.folha.uol.com.br/ colunas/marciorachkorsky/2014/05/1459320-turma-da-pesada-no-condominio.shtml

Rodrigues, D. R. S. R., Conceição, M. I. G., \& Iunes, A. L. S. (2015). Representações sociais do crack na mídia. Psicologia: Teoria e Pesquisa, 31(1), 115-123.

Santos, M. F. S., Aléssio, R. L. S., \& Silva, J. M. M. N. (2009). Os adolescentes e a violência na imprensa. Psicologia: Teoria e Pesquisa, 25(3), 447-452.

Szapiro, A. M., \& Resende, C. M. de A. (2010). Juventude: etapa da vida ou estilo de vida? Psicologia \& Sociedade, 22(1), 43-49.

Taquetti, C. L. (2010). A gestão das políticas de juventude: o caso de Vitória, 2005-2010 (Dissertação de mestrado). Universidade Federal do Espírito Santo, Vitória, ES.

Vala, J. (2004). Representações sociais: para uma psicologia social do pensamento social. In J. Vala \& M. B. Monteiro (Orgs.), Psicologia social. Lisboa: Fundação Calouste Gulbenkian.

Valesan, S. (2015). Apresentação. In J. J. Waiselfisz, Mortes matadas por armas de fogo: mapa da violência 2015. Brasília, DF: Secretaria-Geral da Presidência da República.

Vieira, O. V. (2014. 29 de novembro). Sem medo. Folha de S.Paulo. https://wwwl.folha.uol.com.br/colunas/oscarvilhenavieira/2014/11/1555223-sem-medo.shtml

Waiselfisz, J. J. (2016). Mapa da violência 2016: homicídios por armas de fogo no Brasil. Brasil, DF: Flacso Brasil. http://flacso.org.br/files/2016/08/Mapa2016_armas_web-1.pdf

Zappellini, M. B., \& Feuerschütte, S. G. (2015). O uso da triangulação na pesquisa científica brasileira em administração. Administração: Ensino e Pesquisa, 16(2), 241-273.

José Walter Rego Resende

Mestre em Psicologia pelo Programa de Pós-Graduação em Psicologia da Universidade Federal do Vale do São Francisco (Univasf), Petrolina - PE. Brasil

E-mail: walterresende33@gmail.com

(D) https://orcid.org/0000-0003-4479-6445 
Daniel Henrique Pereira Espíndula

Doutor em Psicologia e docente do Programa de Pós-Graduação em Psicologia da Universidade Federal do Vale do São Francisco (Univasf), Petrolina - PE. Brasil

E-mail: daniel.espindula@univasf.edu.br

(1) https://orcid.org/0000-0003-1912-1171

Endereço para envio de correspondência:

Universidade Federal do Vale do São Francisco. Avenida José de Sá Maniçoba, s/n, Centro. CEP: 56.304-205.

Petrolina - PE. Brasil.

Recebido 20/01/2018

Aceito 29/10/2018

Received 20/01/2018

Approved 29/10/2018

Recibido 20/01/2018

Aceptado 29/10/2018

Como citar: Resende, J. W. R., \& Espíndula, D. H. P. (2020). Juventude em Foco: Representações Sociais da Juventude na Folha de São Paulo. Psicologia: Ciência e Profissão, 40, 1-15. https://doi.org/10.1590/1982-3703003190523

How to cite: Resende, J. W. R., \& Espíndula, D. H. P. (2020). Youth in Focus: Social Representations of Youth in Folha de São Paulo. Psicologia: Ciência e Profissão, 40, 1-15. https://doi.org/10.1590/1982-3703003190523

Cómo citar: Resende, J. W. R., \& Espíndula, D. H. P. (2020). Juventud en Foco: Representaciones Sociales de la Juventud en la Folha de São Paulo. Psicologia: Ciência e Profissão, 40, 1-15. https://doi.org/10.1590/1982-3703003190523 